\title{
Introducción al dossier: "Wittgenstein en el pensamiento social y político" (segunda parte)
}

\author{
Pedro Karczmarczyk, UNLP-CONICET \\ pedrokarcz@hotmail.com
}

En este segundo número del volumen dedicado a la influencia de Wittgenstein en el pensamiento político y social incluimos cuatro artículos y tres reseñas.

El trabajo de João Carlos Salles, "Para uma releitura das Anotacõoes sobre as cores", aborda uno de los textos de Wittgenstein que más han llamado la atención de aquellos preocupados por las diferencias culturales y el relativismo suscitado por el problema de la inconmensurabilidad de los sistemas de descripción de la experiencia. El texto de Salles retoma su trabajo como editor de la edición brasileña de esta obra, lo que le dio la oportunidad de examinar cuidadosamente la edición realizada por Elizabeth Anscombe, encontrando serios puntos de divergencia con la misma ("As Anotações sobre as cores já foram consideradas uma massa de textos amorfa e, portanto, secundárias. Salvo melhor juízo, a edição de Anscombe favorece tal juízo negativo"), examen que lo llevó a realizar una edición diferente del texto del austríaco aparecida con el sello editorial de la Universidad de Campinas en 2009. En este artículo, Salles propone y justifica un recorrido de lectura filológico-problemático de dicha obra. El recorrido propuesto tiene por objetivo que las proposiciones que enuncian imposibilidades gramaticales sobre los colores sean encaradas simultáneamente con la consideración de las certezas triviales, inmunes a la duda, que constituyen el suelo de la experiencia. A partir de allí el texto abonará la que constituye su tesis principal: que necesario no coincide con universal, ya que parecemos a enfrentarnos a una necesidad condicional, dependiente de la contextura de nuestros juegos de lenguaje. La descripción de un recorrido supone identificar un punto de partida y estaciones intermedias, cosa que Salles hace apelando a algunos parágrafos de los manuscritos que no fueron considerados por Anscombe, en los que funda la necesidad de su edición. Una primera gran precisión tiene que ver con el objeto de análisis de las Bemerkungen über die Farben de Wittgenstein. Las mismas, nos dice Salles, no se ocupan tanto 
de las incompatibilidades irrestrictas entre los colores de la clase de las que preocuparon al austriaco luego de la redacción del Tractatus, sino de incompatibilidades restringidas, internas a modelos cromáticos específicos que podrían ser considerados como representaciones perspicuas de la gramática de las proposiciones sobre los colores. El análisis de Salles destaca las dificultades que Wittgenstein encuentra en un análisis fenomenológico à la Goethe, que padece de la unilateralidad de cualquier fenomenología que pretenda aprehender la esencia del color: la de reducir los posibles juegos de lenguaje con colores a un único juego, en el caso del autor de Zur Farbenlebre, al que ocurre en la paleta, postulado como anterior a todas las ocurrencias cromáticas. Pero la unilateralidad de la fenomenología no implica que la misma deba rechazarse absolutamente, sino que debe comprenderse, analizarse gramaticalmente, lo que supone la separación de la necesidad gramatical respecto a la necesidad física, en la que se basa la "autonomía" de la primera. En resumen, se trata de reconocer que en el ámbito de la gramática ya no es posible definir a la necesidad como lo que resulta verdadero en todos los mundos posibles, que ya no se puede identificar la necesidad con la universalidad. Por ello, Salles enfatiza que no hay una fenomenología concebida como la ciencia de la visión y de lo percibido previa a todo lo visible que pueda encontrar su expresión en nuestros juegos de lenguaje. El problema de las incompatibilidades restringidas de las proposiciones sobre los colores se revela así como un ejemplo sobresaliente de aquello que Wittgenstein sostenía en Sobre la certeza acerca de que proposiciones con la forma de proposiciones empíricas pueden formar parte de la lógica de nuestros juegos de lenguaje.

El trabajo de Gustavo Robles, "Juegos de lenguaje y teoría crítica. Sobre la recepción de Wittgenstein en el pensamiento de Albrecht Wellmer”, procura analizar la teoría crítica de Wellmer destacando el lugar fundamental que en la misma posee la recepción de Wittgenstein. Robles destaca sobre todo el rol que le cupo a la recepción de Wittgenstein para establecer un diálogo crítico entre la primera y la segunda generación de frankfurtianos, un puente que parecía roto luego del peculiar giro lingüístico que Habermas le había impuesto a la teoría crítica. Robles destaca el diagnóstico del que parte Wellmer, mostrando cómo una lectura mecanicista de Marx, centrada en el desarrollo de las fuerzas productivas, encontraba su expresión filosófica en el concepto de producción, a raíz de lo cual los intentos críticos de Adorno y Horkheimer de superar dicha 
interpretación quedaron cautivos, a pesar de todo, en las redes de su expresión filosófica última. Frente a ello, Wellmer concuerda con Habermas acerca de la necesidad de deconstruir la filosofía de la conciencia anidada en el paradigma de la producción, que encontraba en el proceso laboral, concebido como la praxis de un sujeto, la auténtica praxis racional. Sólo la deconstrucción del concepto de producción permitiría exhibir las potencialidades emancipatorias anidadas en las estructuras de la interacción simbólica. Hacia los años 1980s, coincidiendo con la emergencia de la crítica posmoderna, la filosofía de Wellmer comienza a tomar una fisionomía peculiar, distanciándose de los intentos de fundamentación normativa de la ética comunicativa llevados adelante por Apel y Habermas para proponer en su lugar una ética sostenida en el diálogo históricamente situado. El defecto principal de las éticas del discurso consiste, según Wellmer, en que intentan fundamentarse en una "razón que se habría emancipado de las condiciones de su verbalidad". En consecuencia, se impone rescatar las condiciones de la verbalidad que la idealización comunicativa pierde de vista, para poder restituir a la ética la mundaneidad que le es inherente. Una ética mundana tendrá como telos al diálogo, concebido como un proceso histórico y práctico de intercambio que busca "eliminar el sinsentido", y no ya al consenso. Dos autores son cruciales en este rescate: Adorno y Wittgenstein. El primero es quien le permite a Wellmer percibir la lógica de la identidad que persiste en los intentos de fundamentación de la ética en el discurso idealizado, abogando por la recuperación de su mundaneidad. El segundo le posibilita a Wellmer reconocer las aporías del pensamiento adorniano, que buscaba llevar a cabo una "crítica sociológica de la racionalidad instrumental" y una "critica psicológica del sujeto", pero sin tener en su horizonte una "crítica del sujeto constituyente de significado". Con Wittgenstein, según Wellmer, la filosofía occidental se vio obligada a reconocer como un factum previo a toda intencionalidad o subjetividad a aquello que el austríaco denomina "formas de vida", y que Wellmer concibe como condición mundana, como un mundo que se nos abre lingüísticamente. Wellmer reconoce que las consecuencias de este factum se pueden encontrar en la lectura de Wittgenstein por Kripke, quien establece la imposibilidad de encontrar un fundamento último para nuestros juegos de lenguaje, distanciándose así una vez más de las éticas discursivas. Pero Wellmer deja pronto de lado la lectura kripkeana de Wittgenstein, para extraer de esta carencia de fundamento una consecuencia cara a las filosofías hermenéuticas: 
la de la apertura inherente de la significación, esto es, el carácter abierto de las reglas que estructuran los juegos de lenguaje. A su vez, esta movilidad inherente del significado remite nuevamente a Adorno: "en la vida del sentido lingüístico -nos dice Wellmer- opera una fuerza mimética mediante la cual lo no idéntico en la realidad se refleja como no idéntico en las significaciones lingüísticas". En consecuencia, un lenguaje común no constituye un punto de partida del diálogo, sino el resultado, siempre frágil, del mismo. Wellmer espera así traducir la crítica posmoderna de la razón en una praxis posmoderna de la razón, una que asuma que lo propio de una cultura democrático-liberal no radica en la posesión de una fundamentación última de los principios liberales y democráticos, sino en aceptar como permanente la posibilidad de discutir cómo deben interpretarse dichos principios. Robles nos muestra así, de manera consistente, las vías por las cuales Wellmer apela a Wittgenstein para tornar mundana la teoría crítica. En consecuencia, "el Wittgenstein de Wellmer -nos dice Robles- es un optimista mundano que se distancia del absolutismo de Apel, del formalismo de Habermas o del pesimismo mesiánico de Adorno."

Por su parte, Natalia Lorio y Andrea Torrano, en su "Filosofía, crítica y práctica de sí: entre Wittgenstein y Foucault", encuentran una afinidad en los modos en los que Wittgenstein y Foucault comprendieron la actividad filosófica, para poner de manifiesto que la misma guarda un carácter de actividad sobre sí mismo, una "práctica de sî" que puede considerarse como una terapéutica en el caso de Wittgenstein y como parrhesía en el de Foucault. Torrano y Lorio intentan comprender los modos diversos y próximos en los que en ambos filósofos se establece la conexión que liga a la filosofía con la crítica, y a éstas con la práctica sobre sí mismo del filósofo o filósofa. Las autoras revisan cuidadosamente diversos estudios sobre los posibles puntos de encuentro entre ambos pensadores, comenzando por un artículo de 1978 de Harry Aron, "Wittgenstein's Impact on Foucault", pasando por los trabajos de Ian Hacking y Arnold Davidson hasta llegar a las dos importantes compilaciones de trabajos, una a cargo de A. Davidson y F. Gros y otra, más reciente, compilada por P. Gillot y D. Lorenzini, publicada en 2016, de la cual incluimos una reseña aparte en este número. Si la preocupación constante de Wittgenstein es esclarecer la relación entre el lenguaje y el mundo y la de Foucault es hacer una historia de las distintas modalidades a través de los cuales los seres humanos se transforman en sujetos, el punto de encuentro entre 
ambos resulta ser cualquier cosa menos evidente. Las autoras descubren sin embargo un conjunto de temas, como la crítica al psicologismo, o la crítica a la concepción doctrinaria de la filosofía, que favorecen en ambos casos una concepción de la filosofía como práctica, como intervención, destacando la inscripción de ambos bajo la categoría de la filosofía del concepto (opuesta a una filosofía del sujeto o de la experiencia). Es sobre todo a partir de la crítica a la concepción tradicional de la filosofía (sistemática y totalizadora) que Lorio y Torrano comprenden el vínculo entre crítica y práctica de sí. En el caso de Wittgenstein nos brindan una sugerente caracterización de su método terapéutico, sobre todo en el Tractatus, en el cual la clarificación del lenguaje, la tarea de dejar de lado "los falsos problemas", configura una terapéutica que, al estar la filosofía desenganchada de la teoría, despeja ciertos problemas filosóficos que no se diluyen empero en la clarificación, sino que, por el contrario, la misma ayuda a que puedan ser asumidos cabalmente como problemas vitales. En el caso de Foucault, las autoras encuentran que la crítica no sólo debe ser entendida como crítica a la filosofía (sistemática, totalizadora), lo que configura una dimensión antifilosófica que puede encontrarse tanto en Wittgenstein como en Foucault, sino como una crítica filosófica que configura una actitud, un ethos, que debe ser asumido por quien se proponga como tarea la indagación filosófica. Si bien para Foucault la tarea fundamental de la filosofía ha sido advertir sobre los peligros del poder, tarea que implica simultáneamente un reconocimiento de las exterioridades constitutivas de la subjetividad y una intervención sobre las mismas, hacia el fin de su vida el francés puso la atención sobre las prácticas espirituales de la antigüedad griega y romana, ocupándose particularmente en la parrbesía, la enunciación franca de la verdad y los riesgos que ello implica. Al explorar esta dimensión del decir filosófico, Foucault reencuentra un vínculo entre verdad y crítica, entre verdad y libertad, que remite a unas dimensiones de la subjetividad que desbordan su concepción puntual: la parrhesía es actitud, una forma de atención, de receptividad, ethos, una serie de ejercicios, es decir, un ser devenido y proyectado. A partir de allí, y de algunas consideraciones análogas a propósito de Wittgenstein, las autoras reivindican la inclusión de ambos pensadores bajo la rúbrica de la filosofía del concepto. En resumidas cuentas, de acuerdo con Torrano y Lorio, la filosofía puede pensarse, en uno y otro filósofo, como un ejercicio espiritual dirigido a modificar la manera de vivir y de ver el mundo. 
Mi propio trabajo en este número "El seguimiento de reglas ¿es la praxis de un sujeto? Wittgenstein y la ciencias sociales" propone una distinción entre dos categorías "práctica de un sujeto" "sujeto de una práctica" con la cual pretendemos llamar la atención sobre el hecho de que, si bien el efecto de descentramiento del sujeto (lo que en el trabajo denominamos crítica de la "problemática antropológica") operado por la filosofía de Wittgenstein es corrientemente reconocido, este reconocimiento está acompañado de formas sutiles de recentramiento, que pueden ser capturadas por la categoría de la praxis de un sujeto. Pretendemos demostrar que Wittgenstein elude con tenacidad cualquier forma de recentramiento que haga del seguimiento de reglas la práctica de un sujeto mediante un análisis detallado de la distinción entre actuar significativo y hábito, y en particular los problemas del límite de la justificación y de la obediencia ciega a reglas en los Cuadernos azuly marrón, que es donde encontramos el tratamiento más claro del asunto. Intentamos mostrar que la elucidación wittgensteiniana exhibe una articulación de niveles de eficacia entre la espontaneidad de los individuos, que los habilita a convertirse en agentes, es decir, en los sujetos de una práctica o juego de lenguaje, al satisfacer los requerimientos que éstos imponen. En la segunda parte de nuestro trabajo utilizamos nuestra distinción para revisar algunas de las interpretaciones más influyentes de Wittgenstein en el pensamiento político y social, intentando poner de manifiesto su compromiso con concepciones que hacen del seguimiento de reglas la práctica de un sujeto, con el consiguiente recentramiento subjetivista que ello implica. Para concluir indicamos que el rechazo de toda teleología que implica la elucidación del seguimiento de reglas cuando se la ve como la actividad de los "sujetos de una práctica" concuerda con la afirmación de la objetividad de la realidad social, es decir, con la operación de definición del objeto científico a través de la cual se han constituido las ciencias hasta hoy conocidas. Ello, y la tesis de la articulación de niveles de eficacia implicada en la elucidación que defendemos, nos dan pie para indicar algunos puntos de contacto entre las tesis de Wittgenstein y las operaciones fundacionales del materialismo histórico.

El volumen incluye además tres reseñas, una revisión de la reciente traducción castellana de Jesús Padilla Gálvez de las Investigaciones filosóficas de Wittgenstein, publicada por la editorial Trotta, a cargo de Esteban Yeray García Mederos; una revisión a cargo de Valentín Huarte del volumen compilado por 
Pascale Gillot y Daniele Lorenzini: Foucault/Wittgenstein: subjectivité, politique, éthique, que reúne los trabajos presentados en un coloquio internacional organizado por la Universidad Paris 1 en 2013, publicado en París por las ediciones del CNRS en 2016 y una reseña del reciente libro de Lo Piparo, F. Il professore Gramsci e Wittgenstein. Il linguaggio e il potere, que sostiene la tesis de la influencia directa de Gramsci sobre Wittgenstein por medio de la lectura de fragmentos de los Cuadernos de la Cárcel que le llegaran a través de Piero Sraffa, publicado en Roma por Donzelli en 2014, realizada por Diego Lanciote. Hay que añadir a las mismas la reseña que incluimos en el número anterior, del libro compilado por Cristina Bosso, El concepto de filosofía en Wittgenstein, publicado en Buenos Aires por la editorial Prometeo en 2015, realizada por Javier Vilanova Arias.

Creemos que podemos decir de este número, y del volumen en general, lo que sosteníamos a propósito del primer número: que los vínculos y las tensiones y las afinidades entre los trabajos que presentamos son múltiples y variados, y que el eje de su relevancia para el pensamiento político y social es un campo fértil para las construcciones y las disputas. Ello constituye, a nuestro entender, una muestra de la vitalidad y de la riqueza de la filosofía de Wittgenstein y una exhibición de lo que la misma nos brinda como una fuente siempre inquietante de problemas y preguntas. 